\section{Comparison between community drug teams with and without inbuilt medical services}

John Strang, Michael Donmall, Adrian Webster, Digby Tantam

Drug Dependence Clinical Research and Treatment Unit, Bethlem Royal and Maudsley Hospital, Beckenham, Kent BR3 3BX John Strang, MRCPSYCH, consultant psychiatrist

Drug Research Unit, Prestwich Hospital, Manchester M25 7BL Michael Donmall, PHD, director

Drug Research Unit, Manchester

Adrian Webster, MSC, research assistant

\section{Walsgrave Hospital,} Coventry CV2 2DX Digby Tantam, MRCPSCYH, professor of psychotherapy

Correspondence to: Dr Strang.

BMf 1991;303:897

Community drug teams have been established across the United Kingdom over the past deacade as part of an effort to increase the local availability of care for drug takers. Staff mostly have backgrounds in community psychiatric nursing and social work; some teams also other medical officer, or they may have arrangements for regular sessions from local general practitioners. A health circular on the development of drug services described various models of medical input. ${ }^{1}$ Two different approaches to medical participation were evident across the North Western region: seven drug teams had inbuilt medical care either from the local consultant psychiatrist or from regular sessions provided by an employed general practitioner and eight operated without designated medical input. Arrangements for medical input were defined by each district before the community drug team was established and so were not a result of subsequent clinical demand. We compared data on the drug takers presenting to drug teams with and without inbuilt medical input.

\section{Methods and results} have regular sessions from a consultant psychiatrist or

During the 15 months of the study (till March 1987) 735 drug takers presented to the seven community drug teams with medical input (medically integrated) and 239 to the eight without distinct medical input (medically independent). Anonymous data on such patients are provided to the regional database ${ }^{2}$ at the point of presentation to the service for all new patients and for those who have been out of contact for more than six months, whom we also categorised as new patients. The table shows the main drugs of misuse of patients in these two groups.

The medically integrated drug teams saw three times as many new drug takers during the study period as did the medically independent teams (average number per team $105 v 30$ ). They saw six times as many heroin users (average number per team $71 v 11$ ), representing twice the proportion of each group's total patient population $(67 \%$ v 35\%). Three times as many amphetamine users were seen by the medically integrated teams (average number per team $16 v 5$ )$16 \%$ of the patient population of the two groups. Similar absolute numbers of solvent users and benzodiazepine users were seen by both types of teams (solvents, 30 and 24 respectively; benzodiazepines, 151 and 85 respectively). The heroin addicts presenting to medically integrated drug teams had used opiates for a shorter time $(2.57 v 3.45$ years, $\mathrm{p}<0.01)$ and a higher proportion injected the drug $(64 \% v 53 \%, \mathrm{p}<0.05)$.

\section{Comment}

Significant differences existed in both the numbers and characteristics of patients presenting to community drug teams with and without integrated medical input.
Summary characteristics of new drug misusers reported by community drug teams to regional database. Values are numbers (percentages ${ }^{\star}$ ) of drug misusers

\begin{tabular}{|c|c|c|c|}
\hline & \multicolumn{3}{|c|}{ Community drug team } \\
\hline & $\begin{array}{c}\text { Medically integrated } \\
(\mathrm{n}=7 ; 735 \text { drug misusers })\end{array}$ & $\begin{array}{r}\text { Medical } \\
(\mathbf{n}=8 ; 23\end{array}$ & $\begin{array}{l}\text { lly independent } \\
39 \text { drug misuers) }\end{array}$ \\
\hline \multicolumn{4}{|c|}{ Main drug of misuse } \\
\hline Heroin & $444(60)$ & & $68(29)$ \\
\hline Injecting & $287(65)$ & $33(49)$ & \\
\hline $\begin{array}{l}\text { Other opiate } \\
\text { Injecting }\end{array}$ & $8(14) 60(8)$ & $19(49)$ & $39(16)$ \\
\hline $\begin{array}{l}\text { Amphetamine } \\
\text { Injecting }\end{array}$ & $38(59) 65(9)$ & $13(52)$ & $25(11)$ \\
\hline Benzodiazepines & $78(11)$ & & $59(25)$ \\
\hline Injecting & 1 (1) & 0 & \\
\hline $\begin{array}{l}\text { Solvent } \\
\text { Injecting }\end{array}$ & $0 \quad 29(4)$ & 0 & $23(10)$ \\
\hline \multicolumn{4}{|c|}{ Any drug of misuse } \\
\hline $\begin{array}{l}\text { Heroin } \\
\text { Iniecting }\end{array}$ & $316(64) 494(67)$ & $44(53)$ & $84(35)$ \\
\hline $\begin{array}{l}\text { Amphetamine } \\
\text { Injecting }\end{array}$ & $72(69) 115(16)$ & $21(55)$ & $38(16)$ \\
\hline $\begin{array}{l}\text { Benzodiazepines } \\
\text { Injecting }\end{array}$ & $1(<1) 151(21)$ & $3(4)$ & $85(36)$ \\
\hline $\begin{array}{l}\text { Solvent } \\
\text { Injecting }\end{array}$ & $0 \quad 30$ & 0 & $24(10)$ \\
\hline
\end{tabular}

*Percentages exclude missing data.

tIncludes methadone (therefore includes former heroin addicts already taking methadone before having been seen by a reporting practitioner).

These differences applied across the range of clinical cases and did not simply reflect different degrees of drug misuse. Thus although roughly equal numbers of people presented with problems related to solvents and to benzodiazepines, medically integrated teams saw more than six times as many heroin users and three times as many amphetamine users, who together constituted five times as many injecting drug misusers. Though our data cannot establish the direction of causality, both the number and the characteristics of drug takers who present to services might be related to the staff mix of a community drug team, specifically to the inclusion of inbuilt medical care.

What is it about medical input to drug teams that might account for the observed difference? Access to facilities for physical care is an unlikely explanation as this was not promoted actively before or during the period of the study. Perhaps the perceived availability of a prescription for substitute drugs - for example, oral methadone for heroin addicts - might account for the attendance of heroin users in particular.

HIV infection is forcing a re-examination of drug services. $^{3.5}$ It is particularly important to make and maintain contact with drug takers (especially those who inject) who are not in contact with community drug teams. ${ }^{34}$ Our data suggest that one step towards achieving these ends might be simply to integrate medical care into community drug teams.

1 Department of Health and Social Security. Models of general practitioner involvement in working with drug misusers (annex 2). In: Preventing the spread of HIV infection among and from injecting drug misusers. London: DHSS spread of HIV infection among andf
1988. (Health circular 88/53.)

2 Donmall MC, Webster A, Tantam D, Strang J. The introduction of community based services for drug misusers: impact and outcome in the north west 1982-86. Report to the Department of Health. London: Institute for the Study of Drug Dependence, 1990

3 Advisory Council on the Misuse of Drugs. AIDS and drug misuse report, part 1. London: HMSO, 1988.

4 Advisory Council on the Misuse of Drugs. AIDS and drug misuse report, part 2. London: HMSO, 1989.

5 Strang J, Stimson GV, eds. AIDS and drug misuse. The challenge for policy and practice in the 1990s. London: Routledge, 1990.

(Accepted 4 fuly 199l) 